\title{
Protection juridique pour médecins
}

\section{Protégez-vous maintenant}

\section{Imaginez donc, ...}

... trois jours après l'achat d'un appareil d'occasion ce dernier tombe en panne.

... I lors d'un accident de la circulation vous êtes blessé, mais la partie adverse récuse toute responsabilité.

... un assureur maladie refuse de vous dédommager selon le tarif pour les prestations médicales que vous avez effectuées.

Même la personne la plus pacifique risque de devoir affronter un jour un différent juridique. Et ce n'est pas toujours facile de savoir qui est dans son bon droit. II s'ensuit parfois d'énormes frais d'avocat, de procès et des revendications.

L'assurance de protection juridique de FMH Insurance Services vous aide à défendre votre bon droit. Les experts et avocats de Protekta sont à vos côtés pour vous conseiller et défendre vos intérêts. De plus l'assurance prend à sa charge les honoraires et frais de procès jusqu'à CHF 250000.- par cas.

\section{Risques assurés}

Protection juridique professionnelle Protection juridique circulation pour Protection juridique privée pour toutes pour médecins indépendants ainsi que toutes les personnes faisant ménage com- les personnes faisant ménage commun avec pour médecins employés et assistants mun avec l'assuré ainsi que les personnes l'assuré. médicaux dans l'exercice de leur fonc- autorisées à conduire un véhicule de l'astion pour le cabinet assuré (y.c. surmédi- suré. calisation).
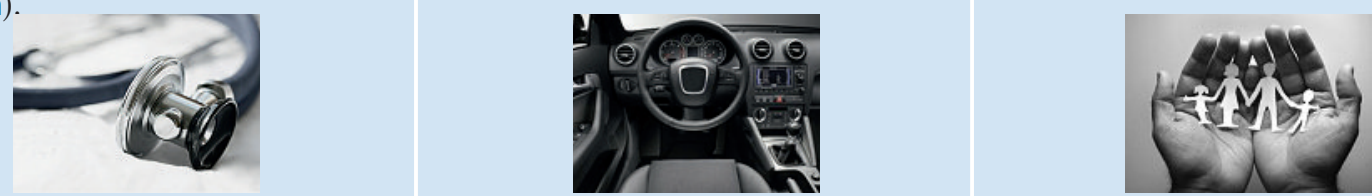

Comandez aujourd'hui encore la proposition afin que vous et votre famille soyez protégés des conséquences d'un litige juridique. Ou appelez-nous afin que nous puissions vous renseigner au sujet de cette assurance ou pour toute autre question dans les domaines de la prévoyance, de la fortune et des assurances.

\section{Talon réponse}

Prénom / Nom

Adresse

PA / Lieu

Date de naissance

Type d'activité lucrative

indépendant

employé

Téléphone privé / cabinet

Atteignable le plus facilement (heure)

Adresse E-Mail

Veuillez me faire parvenir les documents relatifs à la conclusion d'une assurance protection juridique.

Prière de me téléphoner pour un conseil personnalisé.

Je m’intéresse à:
O Planification de la retraite
Prévoyance liée (3a)
C Caisse de pension LPP
Planification financière
O Caisse maladie
O Responsabilité civile prof.

\section{GFMH INSURANCE}

Roth Gygax \& Partner AG @ Service de coordination Moosstrasse 2 a 3073 Gümligen

O 